\title{
Pancreatic neuroendocrine tumours in patients with von Hippel-Lindau disease
}

\author{
Agnieszka Zwolak, ${ }^{1,}$, Joanna Świrska ${ }^{1,2}$, Ewa Tywanek ${ }^{1,2}$, Marta Dudzińska' ${ }^{1}$ Jerzy S. Tarach ${ }^{2}$, \\ Beata Matyjaszek-Matuszek ${ }^{2}$
}

${ }^{1}$ Chair of Internal Medicine and Department of Internal Nursing, Medical University in Lublin, Poland

${ }^{2}$ Department of Endocrinology, Medical University in Lublin, Poland

\begin{abstract}
Von Hippel-Lindau disease is a highly penetrant autosomal genetic disorder caused by a germline mutation in the tumour suppressor gene, manifesting with the formation of various tumours, including neuroendocrine tumours of the pancreas. The incidence of the latter is not very high, varying from $5 \%$ to $18 \%$. To compare, haemangioblastomas and clear cell renal carcinoma are present in $70 \%$ of von Hippel-Lindau patients and are considered the main prognostic factors, with renal cancer being the most common cause of death. However, pancreatic neuroendocrine tumours should not be neglected, considering their malignant potential (different to sporadic cases), natural history, and treatment protocol. This paper aims to review the literature on the epidemiology, natural history, treatment, and surveillance of individuals affected by pancreatic neuroendocrine tumours in von Hippel-Lindau disease. (Endokrynol Pol 2020; 71 (3): 256-259)

Key words: pancreatic neuroendocrine tumours; von Hippel-Lindau disease
\end{abstract}

\section{Introduction}

Von Hippel-Lindau disease (VHL) is a highly penetrant autosomal genetic disorder caused by a germline mutation in the VHL tumour suppressor gene located on the short arm of chromosome 3 . The disease presents with the formation of tumours (both benign and malignant) and cysts in various organs. The incidence of pancreatic neuroendocrine tumours (PNETs) in VHL disease is not very high, varying from 5 to $18 \%$ depending on the study. To compare, haemangioblastomas and clear cell renal carcinoma (RCC) are present in 70\% of VHL patients and are considered as the main prognostic factors, with renal cancer being the most common cause of death [1-5]. However, considering the malignant potential of PNETs and improving life expectance in VHL, it is important to screen VHL patients for PNETs in order to detect them at an early stage $[6,7]$. The paper reviews the literature on the incidence, clinical presentation, and treatment of PNETs in VHL disease.

\section{Pancreatic lesions in von Hippel-Lindau disease}

In total, pancreatic lesions related to VHL are common, with prevalence ranging from 17 to $87 \%$ depending on the study $[1,4,8-10]$. Interestingly, in a group of
52 VHL patients evaluated by Hough, there were six people (12\%) in whom pancreatic involvement was the only abdominal manifestation of the disease [9]. Furthermore, in the study by Hammel, VHL disease was diagnosed accidently in $6 \%$ of patients during imaging examinations performed for unrelated reason [8].

Pancreatic lesions found in VHL disease are a heterogenous group. As well as PNETs, pancreatic true cysts and serous cystadenomas have been described [4]. Furthermore, mixed serous neuroendocrine neoplasms (MSNN) with the components of both serous cyst adenoma and of neuroendocrine tumour can develop [11]. Also a few cases of haemangioblastomas, renal cancer metastases, and a case pancreatic adenocarcinoma have been stated in VHL $[8,12,13]$.

Of all the lesions, cysts are the most common and are found in $17-56 \%$ of the patients during routine screening $[1,14,15]$. At autopsy, the percentage of true cysts in VHL patients is even higher, reaching $72 \%$ $[14,16]$. Typically, the cysts and serous cystadenomas are benign, asymptomatic, and are detected during routine screening of VHL family members. However, they tend to grow in approximately $50 \%$ of patients. In $20 \%$, they may eventually compress pancreatic duct or neighbouring organs $[8,9]$. In the course of pancreatic cyst growth, the development of diabetes mellitus and a case of acute pancreatitis have also been documented 
$[8,17]$. Cysts in VHL disease, as in many other genetic syndromes, are often multiple [8]. Thus, detection of several pancreatic cysts in an imaging examination should always raise suspicion of VHL or another genetic syndrome. According to Hough, the presence of a single pancreatic cyst in a patient with positive VHL family history makes the diagnosis of VHL very probable, whereas multiple cysts make the diagnosis certain [9].

\section{Epidemiology of pancreatic neuroendocrine tumours in von Hippel-Lindau disease}

In the general population, PNETs constitute approximately $5 \%$ of all pancreatic neoplasms [18]. Their incidence in VHL disease is estimated at 5-18\%. However, taking all PNETs together, the possibility of PNET being a part of VHL is evaluated at less than $0.5 \%$ [19]. Pancreatic neuroendocrine tumours in VHL can be located throughout the pancreas [20]. They are often multiple and - typically - non-functioning [4, $14,19,20,21]$. The mean detection age is lower than in sporadic cases. According to available reports, the youngest age at PNET diagnosis was 12 years [22]. In the study by de Mestier the mean age for VHL was 35 years and for sporadic cases -58 years [23]. Similar results were obtained by Blansfield and by Erlic. The latter reported that mean age of recognition of sporadic and syndromic PNETs was 57 and 37 years, respectively. The data on patient sex in PNET differ depending on the study. In the study by Eric, in VHL - women were more commonly affected by the disease than in sporadic cases $(\mathrm{p}=0.01)$. Similarly, Hammel reported that women accounted for $66 \%$ of all VHL-related PNETs. However, in the study by Blansfield the male to female ratio was 1:1.1 (51 cases vs. 57 cases) $[3,8,19]$.

\section{Histopathology of pancreatic neuroendocrine tumours in von Hippel-Lindau disease}

All PNETs, both sporadic and VHL-related, have malignant potential. Histopathologically, they should be evaluated according to the World Health Organisation 2017 classification (a three-degree proliferation-based grading system with evaluation of Ki-67 index) [24]. The tumours are formed from pancreatic islet cells. In VHL disease, PNETs do not present evident hormonal activity [1]. However, in immunochemistry they are positive for chromogranin A and synaptophysin. They can also be positive for somatostatin, pancreatic polypeptide, and inhibin. Interestingly, in VHL, in contrast to many sporadic cases, they are not positive for gastrin [4, 25].

\section{Natural history of pancreatic neuroendocrine tumours in von Hippel-Lindau disease}

Distant metastases are found in $60-90 \%$ of sporadic PNETs, whereas in VHL the incidence of metastases is lower and estimated at $11-20 \%$. The question arises whether this is due to the higher malignant potential of sporadic PNETs or is a consequence of regular imaging studies of the abdomen performed in VHL and thus earlier tumour recognition. Yamasaki points out that sporadic non-functioning PNETs typically grow up to $5 \mathrm{~cm}$ in diameter until they are detected, because there are no previous alert hormonal symptoms [26]. In the study by de Mestier the median Ki index for PNETs in VHL and in sporadic cases was 3\% and 4\%, respectively, and this difference was not statistically significant $(p=0.95)$. Furthermore, lymph node metastases were detected in $43 \%$ and $30 \%$, respectively ( $p=0.45$ ). Generally, VHL-related PNETs can be classified to G1 or G2 according to WHO grading [23]. However, a case of G3 PNET was described by Japanese authors with Ki67 index $=40 \%$. At the diagnosis, the tumour size was $4 \mathrm{~cm}$ and liver metastases were already detected [27]. In the observation study performed by de Mestier, VHL-related PNETs smaller than $15 \mathrm{~mm}$ in diameter did not progress during 10-year follow-up [23]. According to Blansfield, in VHL, the exon 3 mutation determines a more aggressive course and metastases development. Also, metastases development is more likely in tumours larger than $3 \mathrm{~cm}$ in diameter [3]. Mixed serous neuroendocrine neoplasms seem to have higher malignant potential than PNETs alone [11]. Generally, PNETs are regarded as a rare cause of death in VHL [3]. Renal clear cell cancer giving metastases in approximately $45 \%$ of VHL patients is the commonest cause of morbidity in VHL [14, 28, 29].

\section{Imaging studies of pancreatic neuroendocrine tumours in von Hippel-Lindau disease}

Pancreatic neuroendocrine tumours, being richly vascularised, present as strongly enhanced tumours in dynamic computer tomography with iodine contrast [9, $10,18]$. On MRI, they are hypointense in T1 images and hyperintense in T2 scans. Both CT and MR examination seem comparable in terms of detecting primary pancreatic lesion. Yet, MRI is considered more effective in finding metastases in the liver [10,21]. Typically, PNETs are well circumscribed and encapsulated [1].

Endoscopic ultrasound exploration is a very sensitive method enabling pancreatic tumour detection. Furthermore, there is a possibility of performing tumour biopsy during the examination thus enabling establishment of the NET diagnosis [24]. 
Radioisotope diagnostic examinations are the most sensitive methods used in evaluation of NETs, including PNETs. Somatostatin scintigraphy is characterised by approximately $80 \%$ sensitivity. It has the highest affinity to somatostatin receptors type 2 (SSTR2), which are present in PNETs. A less available but even more sensitive and specific method is Ga-68 somatostatin receptor PET/CT. Apart from visualising PNETs, Ga-68 somatostatin receptor PET/CT can also be useful in VHL in detecting coexisting pheochromocytoma or neuroblastoma [30, 31].

Fluorodeoxyglucose-positron emission tomography (PET-FDG) can be particularly helpful in finding PNETs smaller than $1 \mathrm{~cm}$ in diameter or in visualising small hepatic metastases that cannot yet be seen in classic contrast-enhanced CT scans. Added to this, in certain situations, PET-FDG, unlike classic CT, may help to differentiate serous pancreatic adenomas from PNETs, thus helping to decide whether to operate the patient or not $[10,32,33]$.

\section{Treatment of pancreatic neuroendocrine tumours in von Hippel-Lindau disease}

Generally, sporadic non-secreting neuroendocrine tumours of the pancreas should be removed when they are more than $20 \mathrm{~mm}$ in diameter. Smaller tumours can be observed if they have not got radiological or histopathological features of malignancy [21,24]. The data on PNET treatment in VHL are limited and based only on retrospective analysis. Prospective validated trials are missing. Generally, surgery should be recommended more carefully because the tumours are often multiple, and the patient is affected by more serious other organs' lesions related to VHL. The patient's general life expectancy has to be taken into consideration as well as the effect of pancreatic tumour removal on his/her survival. On the one hand, tumour removal decreases the risk of the metastases; on the other hand, the surgery is related to certain complications. Possible complications related to PNET removal are pancreatic fistulas - their risk is higher in the case of VHL-related than in sporadic PNETs. Furthermore, perioperative infections are common [3, 21, 23]. The development of diabetes mellitus or loss of pancreatic exocrine function is also possible. Libutti et al. proposed tumour removal in the following situations: neoplasm diameter $>30 \mathrm{~mm}(20 \mathrm{~mm}-$ if the tumour is located in the pancreatic head), during abdominal surgery for an unrelated reason, or if the tumour is symptomatic (despite its size) [15]. According to Blansfield, there are three major factors that determine the risk of metastases: tumour size, exon 3 mutation, and mean doubling time. Thus, following Blansfield, in patients with primary lesion smaller than
$3 \mathrm{~cm}$, without exon 3 mutation, and with doubling time shorter than 500 days a non-operative approach seems more reasonable with control image study repeated every two or three years. In patients who have one of the above factors, observation is also recommended but the imaging study should be repeated more frequently - every six months. Only patients who meet two or three criteria should be qualified for the surgery because they are at higher risk of developing metastases [3]. Treatment with somatostatin analogues is well documented in non-secreting PNETs in tumour stabilisation [24, 34]. Promising results were obtained in a case of multifocal PNETs in VHL where six-month therapy with lanreotide significantly diminished the size of the tumours [35]. In advanced disease, as in sporadic PNETs, treatment includes peptide receptor radioligand therapy (PRRT), chemotherapy, and molecularly targeted therapy [24]. In patients with VHL, who are affected at the same time by PNET and other VHL-related tumours, (pheochromocytoma, RCC, haemangioblastoma) sunitinib therapy led to mass reduction in all tumor types [36].

\section{Follow-up}

The surveillance schedule in VHL includes, among others, searching for typical abdominal lesions. Typically, the image investigation of the abdomen begins in the age of eight years with annual ultrasound. Starting from the age of 16 years, abdominal MR once every two years is recommended [37].

\section{Conclusion}

Pancreatic neuroendocrine tumours in VHL disease are not very common, and thus there are few data on their management. Further studies are necessary in order to implement the ideal treatment schedule and surveillance algorithm.

\section{Declaration of interest}

The authors declare that there is no conflict of interest that could be perceived as prejudicing the impartiality of this review.

\section{Funding}

This work did not receive any specific grant from any funding agency in the public, commercial, or not-for-profit sector.

\section{References}

1. Lonser RR, Glenn GM, Walther M, et al. von Hippel-Lindau disease. Lancet. 2003; 361(9374): 2059-2067, doi: 10.1016/S0140-6736(03)13643-4, indexed in Pubmed: 12814730. 
2. Maher ER, Neumann HPh, Richard S. von Hippel-Lindau disease: a clinical and scientific review. Eur J Hum Genet. 2011; 19(6): 617-623, doi: 10.1038/ejhg.2010.175, indexed in Pubmed: 21386872.

3. Blansfield JA, Choyke L, Morita SY, et al. Clinical, genetic and radiographic analysis of 108 patients with von Hippel-Lindau disease (VHL) manifested by pancreatic neuroendocrine neoplasms (PNETs). Surgery. 2007; 142(6): 814-8; discussion 818.e1, doi: 10.1016/j.surg.2007.09.012, indexed in Pubmed: 18063061.

4. Cassol C, Mete O. Endocrine manifestations of von Hippel-Lindau disease. Arch Pathol Lab Med. 2015; 139(2): 263-268, doi: 10.5858/arpa.2013-0520-RS, indexed in Pubmed: 25611110.

5. Woodward ER, Maher ER. Von Hippel-Lindau disease and endocrine tumour susceptibility. Endocr Relat Cancer. 2006; 13(2): 415-425, doi: 10.1677/erc.1.00683, indexed in Pubmed: 16728571.

6. Binderup ML, Jensen AM, Budtz-Jørgensen E, et al. Survival and causes of death in patients with von Hippel-Lindau disease. J Med Genet. 2017; 54(1): 11-18, doi: 10.1136/jmedgenet-2016-104058, indexed in Pubmed: 27539272.

7. Wilding A, Ingham SL, Lalloo F, et al. Life expectancy in hereditary cancer predisposing diseases: an observational study. J Med Genet 2012; 49(4): 264-269, doi: 10.1136/jmedgenet-2011-100562, indexed in Pubmed: 22362873.

8. Hammel P, Vilgrain V, Terris B, et al. Pancreatic involvement in von Hippel-Lindau disease. Gastroenterology. 2000; 119(4): 1087-1095, doi: 10.1053/gast.2000.18143, indexed in Pubmed: 11040195.

9. Hough DM, Stephens DH, Johnson CD, et al. Pancreatic lesions in von Hippel-Lindau disease: prevalence, clinical significance, and CT findings. AJR Am J Roentgenol. 1994; 162(5): 1091-1094, doi: 10.2214/ajr.162.5.8165988, indexed in Pubmed: 8165988

10. Park TY, Lee SK, Park JS, et al. Clinical features of pancreatic involvement in von Hippel-Lindau disease: a retrospective study of 55 case in a single center. Scand J Gastroenterol. 2015; 50(3): 360-367, doi: 10.31 09/00365521.2014.992364, indexed in Pubmed: 25562111.

11. Yamashima M, Ozawa E, Ohnita K, et al. Hepatobiliary and Pancreatic: Pancreatic mixed serous neuroendocrine neoplasm in von Hippel-Lindau disease. J Gastroenterol Hepatol. 2018; 33(11): 1821 doi: 10.1111/jgh.14274, indexed in Pubmed: 29888404.

12. Fill WL, Lamiell JM, Polk NO. The radiographic manifestation of von Hippel-Lindau disease. Radiology. 1979; 133(2): 289-295, doi: 10.1148/133.2.289, indexed in Pubmed: 573913.

13. Lamiell JM, Salazar FG, Hsia YE. von Hippel-Lindau disease affecting 43 members of a single kindred. Medicine (Baltimore). 1989; 68(1): 1-29, doi: 10.1097/00005792-198901000-00001, indexed in Pubmed: 2642584.

14. Charlesworth M, Verbeke CS, Falk GA, et al. Pancreatic lesions in von Hippel-Lindau disease? A systematic review and meta-synthesis of the literature. J Gastrointest Surg. 2012; 16(7): 1422-1428, doi: 10.1007/s11605-012-1847-0, indexed in Pubmed: 22370733.

15. Libutti SK, Choyke PL, Bartlett DL, et al. Pancreatic neuroendocrine tumors associated with von Hippel Lindau disease: diagnostic and management recommendations. Surgery. 1998; 124(6): 1153-1159, doi: 10.1067/msy.1998.91823, indexed in Pubmed: 9854597.

16. Horton WA, Wong V, Eldridge R. Von Hippel-Lindau disease: clinical and pathological manifestations in nine families with 50 affected members. Arch Intern Med. 1976; 136(7): 769-777, doi: 10.1001/archinte.136.7.769, indexed in Pubmed: 945722

17. Tenner S, Roston A, Lichtenstein D, et al. Von Hippel-Lindau disease complicated by acute pancreatitis and Evan's syndrome. In J Pancreatol. 1995; 18(3): 271-275, doi: 10.1007/BF02784952, indexed in Pubmed: 8708400

18. Dąbkowski K, Kos-Kudła B, Andrysiak-Mamos E, et al. Cystic pancreatic neuroendocrine tumours - a gastroenterologist's point of view. Endokrynol Pol. 2018; 69(3): 320-325, doi: 10.5603/EP.2018.0034, indexed in Pubmed: 29952422.

19. Erlic Z, Ploeckinger U, Cascon A, et al. VHL-ICT Consortium, German NET Registry. Systematic comparison of sporadic and syndromic pancreatic islet cell tumors. Endocr Relat Cancer. 2010; 17(4): 875-883, doi: 10.1677/ERC-10-0037, indexed in Pubmed: 20660572

20. Safo AOF, Pambuccian SE. Pancreatic manifestations of von Hippel-Lindau disease. Arch Pathol Lab Med. 2010; 134(7): 1080-1083, doi: 10.1043/2009-0172-RS.1, indexed in Pubmed: 20586642

21. Tamura K, Nishimori I, Ito T, et al. Diagnosis and management of pancreatic neuroendocrine tumor in von Hippel-Lindau disease. World
J Gastroenterol. 2010; 16(36): 4515-4518, doi: 10.3748/wjg.v16.i36.4515, indexed in Pubmed: 20857520.

22. Langrehr JM, Bahra M, Kristiansen G, et al. Neuroendocrine tumo of the pancreas and bilateral adrenal pheochromocytomas. A rare manifestation of von Hippel-Lindau disease in childhood. J Pediatr Surg. 2007; 42(7): 1291-1294, doi: 10.1016/j.jpedsurg.2007.02.029, indexed in Pubmed: 17618900.

23. de Mestier L, Gaujoux S, Cros J, et al. Long-term Prognosis of Resected Pancreatic Neuroendocrine Tumors in von Hippel-Lindau Disease Is Favorable and Not Influenced by Small Tumors Left in Place. Ann Surg. 2015; 262(2): 384-388, doi: 10.1097/SLA.0000000000000856, indexed in Pubmed: 25185468.

24. Kos-Kudła B, Blicharz-Dorniak J, Strzelczyk J, et al. Consensus Conference, olish Network of Neuroendocrine Tumours. Pancreatic neuroendocrine neoplasms - management guidelines (recommended by the Polish Network of Neuroendocrine Tumours). Endokrynol Pol. 2013; 64(6): 459-479, doi: 10.5603/EP.2013.0031, indexed in Pubmed: 24431118.

25. Lubensky IA, Pack S, Ault D, et al. Multiple neuroendocrine tumors of the pancreas in von Hippel-Lindau disease patients: histopathological and molecular genetic analysis. Am J Pathol. 1998; 153(1): 223-231, doi: 10.1016/S0002-9440(10)65563-0, indexed in Pubmed: 9665483

26. Igarashi $\mathrm{H}$, Ito $\mathrm{T}$, Nishimori I, et al. Clinical characteristics of pancreatic neuroendocrine tumors in Japanese patients with von Hippel-Lindau disease. Pancreas. 2006; 33(4): 382-385, doi: 10.1097/01. mpa.0000240604.26312.e4, indexed in Pubmed: 17079943.

27. Miki M, Kawabe K, Igarashi H, et al. An Advanced Well-differentiated Pancreatic Neuroendocrine Carcinoma (NET-G3) Associated with Von Hippel-Lindau Disease. Intern Med. 2018; 57(14): 2007-2011, doi: 10.2169/internalmedicine.0416-17, indexed in Pubmed: 29491307.

28. Grubb RL, Choyke PL, Pinto PA, et al. Management of von Hippel-Lindau-associated kidney cancer. Nat Clin Pract Urol. 2005; 2(5): 248-255, doi: 10.1038/ncpuro0179, indexed in Pubmed: 16474836.

29. Walther MM, Choyke PL, Glenn G, et al. Renal cancer in families with hereditary renal cancer: prospective analysis of a tumor size threshold for renal parenchymal sparing surgery. J Urol. 1999; 161(5): 1475-1479, doi: 10.1016/s0022-5347(05)68930-6, indexed in Pubmed: 10210376.

30. Kroiss A, Putzer D, Uprimny $C$, et al. Functional imaging in phaeochromocytoma and neuroblastoma with 68Ga-DOTA-Tyr3-octreotide positron emission tomography and 123I-metaiodobenzylguanidine: a clarification. Eur J Nucl Med Mol Imaging. 2012; 39(3): 543 doi: 10.1007/s00259-011-1962-2, indexed in Pubmed: 22237841.

31. Oh JR, Kulkarni H, Carreras C, et al. Ga-68 Somatostatin Receptor PET/CT in von Hippel-Lindau Disease. Nucl Med Mol Imaging. 2012; 46(2): 129-133, doi: 10.1007/s13139-012-0133-0, indexed in Pubmed: 24900047

32. Sizdahkhani S, Feldman MJ, Piazza MG, et al. Somatostatin receptor expression on von Hippel-Lindau-associated hemangioblastomas offers novel therapeutic target. Sci Rep. 2017; 7: 40822, doi: 10.1038/srep40822, indexed in Pubmed: 28094316.

33. Sadowski SM, Weisbrod AB, Ellis R, et al. Prospective evaluation of the clinical utility of 18-fluorodeoxyglucose PET CT scanning in patients with von hippel-lindau-associated pancreatic lesions. J Am Coll Surg. 2014; 218(5): 997-1003, doi: 10.1016/j.jamcollsurg.2014.01.004, indexed in Pubmed: 24661849.

34. Rinke A, Müller HH, Schade-Brittinger C, et al. PROMID Study Group. Placebo-controlled, double-blind, prospective, randomized study on the effect of octreotide LAR in the control of tumor growth in patients with metastatic neuroendocrine midgut tumors: a report from the PROMID Study Group. J Clin Oncol. 2009; 27(28): 4656-4663, doi: 10.1200/JCO.2009.22.8510, indexed in Pubmed: 19704057.

35. O Toole SM, Drake WM. Response to Somatostatin Analog Therapy in a Patient With von Hippel-Lindau Disease and Multiple Pancreatic Neuroendocrine Tumors. Pancreas. 2017; 46(7): e57 doi: 10.1097/MPA.0000000000000865, indexed in Pubmed: 28697140.

36. Yuan $G$, Liu $Q$, Tong $D$, et al. A retrospective case study of sunitinib treatment in three patients with Von Hippel-Lindau disease. Cancer Biol Ther. 2018; 19(9): 766-772, doi: 10.1080/15384047.2018.1470732, indexed in Pubmed: 29947576.

37. Varshney N, Kebede AA, Owusu-Dapaah H, et al. A Review of Von Hippel-Lindau Syndrome. J Kidney Cancer VHL. 2017; 4(3): 20-29, doi: 10.15586/jkcvhl.2017.88, indexed in Pubmed: 28785532. 